\title{
CARACTERIZAÇÃO E PROPRIEDADES DA LINHAÇA (Linum usitatissimun L.) E SUBPRODUTOS
}

\begin{abstract}
Este trabalho de revisão de literatura teve como objetivo levantar informações sobre as características e propriedades da linhaça (Linum usitatissimun L.) e subprodutos para o consumo humano. Foram abordados aspectos como origem, conceito, composição físico-química, características sensoriais, processamento e armazenamento, recomendações nutricionais e aspectos microbiológicos e legais desse alimento funcional. Apesar do alto valor nutricional, principalmente devido a sua elevada concentração de $\omega-3$, o consumo da linhaça ainda é baixo, bem como sua adição em produtos alimentícios por parte das indústrias. Torna-se relevante estudo aprofundado sobre os atributos da linhaça com o intuito de aumentar sua ingestão em razão dos seus inúmeros benefícios.
\end{abstract}

PALAVRAS-CHAVE: ALIMENTOS FUNCIONAIS; LINHAÇA; NUTRIÇÃO.

* Professora, Doutora em Tecnologia de Alimentos, Departamento de Nutrição, Setor de Ciências da Saúde, Universidade Estadual do Centro-Oeste (UNICENTRO), Guarapuava, PR (e-mail: nutridai@hotmail.com).

** Professora, Doutora em Tecnologia de Alimentos, Departamento de Tecnologia de Alimentos, Faculdade de Engenharia de Alimentos, Universidade Estadual de Campinas (UNICAMP), Campinas, SP (e-mail: marise@fea.unicamp.br). 


\section{INTRODUÇÃo}

O avanço crescente do mercado dos produtos naturais, aliado aos novos hábitos alimentares dos consumidores preocupados com a prevenção de doenças, direcionou a pesquisa da indústria alimentícia para a busca por produtos mais saudáveis. Nesse contexto, os alimentos funcionais ganharam destaque pelos efeitos benéficos que promovem à saúde (ANJO, 2004).

Segundo Carrara et al. (2009), alimentos funcionais são aqueles que em virtude de componentes fisiologicamente ativos promovem benefícios para saúde. Esses alimentos devem fazer parte da dieta habitual, de forma correta, pois seu benefício depende da interação entre seus componentes e a quantidade ingerida.

A linhaça (Linum usitatissimum L.), considerada alimento com alegação funcional destacase pela presença do ácido graxo $\omega$-3, fibras, lignanas e proteínas (TARPILA et al., 2002; HUSSAIN et al., 2006; OOMAH, DER e GODFREY, 2006), porém seu consumo é pequeno devido à falta de hábito alimentar e, também pela carência de informações dos consumidores.

O objetivo deste estudo foi revisar a literatura sobre a origem, características, propriedades físico-químicas, sensoriais, processamento e armazenamento, recomendações nutricionais e aspectos microbiológicos e legais da linhaça (Linum usitatissimum L.).

\section{ORIGEM}

Cultura antiga, a linhaça tem sido utilizada como alimento, fibras e tecidos. Cerca de 200 espécies de Linum (linho ou linhaça) são conhecidas (CARTER, 1993). Na América do Norte, o termo preferido para linhaça é o linho (usado mais para tecidos), enquanto que os europeus usam o termo linho oleaginoso comestível (MORRIS e VAISEY-GENSER, 2003).

A linhaça (Linum usitatissimum) pertence à família Linaceae (MORRIS e VAISEY-GENSER, 2003; TRUCOM, 2006), sendo utilizada para consumo humano e também animal. Os primeiros registros históricos da linhaça informam seu aparecimento em 9000-8000 a.C. no Irã (HELBAEK, 1969), Turquia (VAN ZEISTE, 1972), Síria (HILIMAN, 1975) e na Jordânia (HOPF, 1983; ROLLEFSON et al., 1985). O primeiro uso da linhaça como o alimento pode ter sido como ingrediente de pães (STITT, 1994) e como laxante (JUDD, 1995).

\section{CARACTERIZAÇÃO}

Planta herbácea que varia de $30 \mathrm{~cm}$ a $130 \mathrm{~cm}$ de altura, a linhaça apresenta talos eretos, folhas estreitas e flores de coloração azul, vermelha ou branca. $O$ fruto consiste de cápsula globosa, da qual saem as sementes brilhantes e planas (CREDIDIO, 2005).

As sementes de linhaça apresentam duas variedades - marrom e dourada. A cor das sementes é determinada pela quantidade de pigmentos presentes, recurso que pode ser alterado por práticas de reprodução normal da planta (MORRIS, 2007). Ressalta-se que as condições de armazenamento podem afetar a cor, alterando o uso final da linhaça.

A variedade marrom tem sido cultivada em regiões de clima quente e úmido, como o Brasil, e a dourada em regiões frias como o norte dos Estados Unidos (EUA) e o Canadá. No cultivo da linhaça marrom são utilizados agrotóxicos, o que não ocorre com a variedade dourada (LIMA, 2008). O plantio da linhaça ocorre nos meses de outono (abril a junho) e a colheita nos meses de primavera e verão (novembro a dezembro) (TRUCOM, 2006).

A produção mundial de linhaça encontra-se entre 2.300 .000 e 2.500 .000 toneladas anuais. O Canadá destaca-se com produção de 930.1 mil toneladas até dezembro de 2009 (FLAX COUNCIL OF CANADÁ, 2010), seguido pelos Estados Unidos, Índia, China, Ucrânia, Rússia, Bélgica, França e Alemanha (TRUCOM, 2006). Na América do Sul, o maior produtor é a Argentina (JACINTO, 
2007). No Brasil, a linhaça é produzida, principalmente, no noroeste gaúcho, sendo utilizada para a fabricação de tecidos, óleos para tinturas, cosméticos, medicamentos e para a alimentação animal e humana (TRUCOM, 2006). Até 2005, existia no Brasil somente o plantio da variedade de cor marrom-avermelhada. No final de 2006 ocorreu a primeira colheita (de 100 toneladas) da variedade dourada (de cor marrom-claro dourada), até então importada do Canadá (TRUCOM, 2006).

As expectativas no segmento da alimentação humana são promissoras, acreditando-se que o consumo de semente de linhaça no Brasil cresça cerca de $10 \%$ ao ano. Supõe-se que somente $2 \%$ dos brasileiros conheçam os benefícios da linhaça para a manutenção da saúde. Em países de grande produção, como os EUA e o Canadá, calcula-se que a demanda por esse alimento seja de dez a vinte vezes maior que no Brasil (TRUCOM, 2006).

As dimensões das sementes de linhaça variam de cerca de 3,0-6,4 mm de comprimento, 1,8-3,4 mm de largura e 0,5-1,6 mm de espessura (FREEMAN, 1995). A semente apresenta dois cotilédonos achatados, que constituem a maior parte do embrião. O embrião é cercado pelo revestimento de semente, que consiste em casca e camada aderente de endosperma. Casca e cotilédones podem ser utilizados separadamente como ingredientes funcionais (OOMAH e MAZZA, 1997; WIESENBORN et al., 2002). Oomah e Mazza (1997) relataram que o processo de descascar a semente diminuiu significativamente a capacidade de absorção de água e viscosidade da linhaça.

Conforme a World Health Organization/Food Agriculture Organization (WHO/FAO, 1995), Morris e Vaisey-Genser (2003) e Roy, Lundy e Eriksen (2007) a linhaça é comercializada, principalmente, como semente lisa inteira ou moída grosseiramente na forma de farinha. Esse ingrediente pode ser utilizado em vários produtos alimentícios, como pães e biscoitos (MACIEL, PONTES e RODRIGUES, 2008), macarrão (LEE e LIP, 2003), doces, chocolate (KOZLOWSKA, 1989), cereais, coberturas de saladas (CARTER, 1993), com lanche "in natura" (AHMED, 1999) em bolos (LEE, INGLETT e CARRIERE, 2004b) e sorvetes (HALL e SCHWARZ, 2002), entre outros. Carne e produtos cárneos com a adição de linhaça estão sendo muito estudados (SANTOS et al., 2008; VALENCIA et al., 2008; GUILLEVIC, KOUBA e MOUROT, 2009).

O óleo de linhaça está disponível em lojas de alimentos saudáveis e supermercados, vendido em garrafas para uso em saladas ou em cápsulas para serem utilizados como suplementos de dieta. Esse óleo é produzido por "pressão a frio" da semente de linhaça, com temperatura máxima permitida de $35^{\circ} \mathrm{C}$. Normalmente é engarrafado em recipientes à prova de luz para evitar a oxidação fotoquímica e refrigerado para limitar a auto-oxidação (MORRIS e VAISEY-GENSER, 2003; ROY, LUNDY e ERIKSEN, 2007).

Os componentes da linhaça que contribuem para a saúde incluem as lignanas (diglicosídeo secoisolariciresinol - SDG, forma predominante e considerado potente fitoestrógeno) (SPENCE et al., 2003), ácido graxo $\alpha$-linolênico ( $\omega$-3) e polissacarídeos (goma ou fibra). Esse alimento também tem sido correlacionado com a diminuição do risco de doença cardiovascular (ABDEL-RAHMAN et al., 2009; PAN et al., 2009), hiperlipidemias (ABDEL-RAHMAN et al., 2009) e câncer (THOMPSON et al., 2005; ABDEL-RAHMAN et al., 2009). Além disso, apresenta atividade antiviral e bactericida (ADLERCREUTZ et al., 1986), atividade anti-inflamatória (RANICH, BHATHENA e VELASQUES, 2001; ZHAO et al., 2004), efeito laxante (CUNNANE et al., 1995) e de prevenção dos sintomas da menopausa e osteoporose (KURZER e XU, 1997; GRIEL et al., 2007).

\section{COMPOSIÇÃO FÍSICO-QUÍMICA}

As sementes da cor marrom e dourada são praticamente idênticas em seu conteúdo de nutrientes (CANADIAN GRAIN COMMISSION, 2001). As diferenças na composição química são pequenas e, provavelmente, resultado de distintas condições de cultivo.

A linhaça, semente oleaginosa, é rica em gordura, fibra dietética e proteínas. Sua composição em média é de $41 \%$ de gordura, $28 \%$ de fibra alimentar total, $20 \%$ de proteína, $7,7 \%$ de 
umidade, $3,5 \%$ de cinzas e $1 \%$ de açúcares simples. A quantidade de gordura na linhaça pode variar de 34-47\%, dependendo da localização, cultivo e condições ambientais (OOMAH e MAZZA, 1998; MORRIS e VAISEY-GENSER, 2003; DAUN et al., 2003; FITZPATRICK, 2006). Geadas precoces ou tardias, calor ou períodos de seca podem ter efeitos negativos sobre a qualidade da semente (DAUN et al., 2003), gerando teores de óleo significativamente menores (GUBBELS, BONNER e KENASCHUK, 1994). Além disso, concentrações mais elevadas de ácido graxo palmítico (C16:0), linoleico $(\mathrm{C} 18: 2, \omega-6)$ e a-linolenico $(\mathrm{C} 18: 3)$ e menor de ácido oleico (C18:1) foram observadas prejudicando as sementes.

Com seu perfil único de ácidos graxos, a linhaça é pobre em ácidos graxos saturados. Apenas $9 \%$ dos ácidos graxos totais da linhaça são saturados. O nível de monoinsaturados (MUFA) desejáveis também é modesto, em torno de 18\%, mas apresenta ótimo perfil de ácidos graxos poliinsaturados (PUFA), em média 73\% (MORRIS e VAISEY-GENSER, 2003; MORRIS, 2007; MADHUSUDHAN, 2009).

O ácido graxo essencial a-linolenico, responsável por $40 \%$ a $60 \%$ dos ácidos graxos do óleo da linhaça, torna esse alimento uma das mais ricas fontes desse nutriente (MADHUSUDHAN, 2009). O ácido graxo essencial $\omega-6$ também está presente em quantidade menor (16\%). Devido ao elevado teor de $\alpha$-linolênico, a linhaça apresenta relação $\omega-6 / \omega-3$ bastante favorável de 0.3:1 (MORRIS e VAISEY-GENSER, 2003).

Wanasundara, Wanasundara e Shahidi (1999) relataram que os lipídios neutros (acilglicerídeos e ácidos graxos) constituem $96 \%$ do total de lipídios da linhaça, enquanto lipídios polares (glicolipídios e fosfolipídios) são responsáveis por 1,4\%.

A casca, principal fonte de ácido palmítico, apresenta conteúdo relativamente baixo de óleo (OOMAH e MAZZA, 1997). Baixo conteúdo de ácido oleico e a-linolênico e alto de ácido linoleico estão presentes no embrião, comparados com a semente inteira. Porém, as sementes com ou sem casca apresentam valores semelhantes de ácido graxo a-linolênico.

O teor de proteína da semente de linhaça, em média de 10,5\% a 31\% (OOMAH e MAZZA, 1993), pode variar entre locais e cultivares devido à genética e ao ambiente. Krause, Schults e Dudek (2002) relataram que a farinha de linhaça de semente descascada contém teor de proteína de $50 \%$.

As principais proteínas da linhaça são a albumina e a globulina. Segundo Madhusudhan e Singh (1983), a albumina compõe $20 \%$ da proteína total da linhaça, podendo variar até $40,2 \%$ (SAMMOUR, 1999). Marcone, Kakuda e Yada (1998) evidenciaram que a fração globulina compõe $73,4 \%$ da proteína total. A linina, principal globulina, é menos solúvel que a albumina (MORRIS e VAISEY-GENSER, 2003).

Em relação ao perfil de aminoácidos, a linhaça é composta por teor relativamente elevado em arginina, ácido aspártico e ácido glutâmico. A lisina, metionina e cistina são considerados os aminoácidos limitantes desse alimento, sendo deficiente, também, em aminoácidos sulfurados (HALL, TULBEK e XU, 2006).

A semente de linhaça, apesar de conter cerca de $30 \%$ de carboidratos totais, não pode ser considerada alimento glicêmico em razão de estar isenta de amidos e de seu baixo teor de açúcar (1 a $2 \%$, dependendo da variedade). Os outros carboidratos da linhaça (fibras dietéticas) não são alterados pelo processo digestivo, ou seja, não geram glicose ou energia direta (TRUCOM, 2006).

Cerca de 28 a 40\% do peso total da linhaça corresponde à fibra alimentar (em $100 \mathrm{~g}$ de peso seco) (CASTRO, BARROSO e SINNECKER, 2005; RUDKOWSKA e JONES, 2007). Um terço da fibra da linhaça é solúvel (6 a $11 \mathrm{~g} / 100 \mathrm{~g}$ ) em água, consistindo principalmente de goma de mucilagem. O restante é insolúvel (17 a $22 \mathrm{~g} / 100 \mathrm{~g}$ ) em água e constituído, principalmente, de polissacarídeos não gomosos como celulose e lignina (MORRIS e VAISEY-GENSER, 2003; MORRIS, 2007).

A mucilagem da linhaça, associada com a casca, constitui goma composta de polissacarídeos ácidos e neutros. A fração neutra contém principalmente, xilose $(62,8 \%)$, sendo a 
fração ácida da semente de linhaça formada preponderantemente de ramnose $(54,5 \%)$ e de galactose $(23,4 \%)$ (CUI, MAZZA e BILIADERIS, 1994). Estudo realizado por Warrand et al. (2005) constatou que os monossacarídeos neutros apresentam mistura de três grandes famílias de polímeros, com arabinoxilanos na razão constante de 0,24 e outros tipos de resíduos de galactose e fucose nas cadeias laterais. Rendimentos de hidrólise ácida, também apresentaram xilose, galactose, arabinose, ramnose e ácido galacturônico, fucose e glucose (BEMILLER, 1973).

Oomah, Kenaschuck e Mazza (1995) relataram variação (3,6-8\%) no conteúdo de polissacarídeos solúveis em água de linhaças de diferentes regiões geográficas e cultivares. A glicose destacou-se como o principal monossacarídeo na goma de semente de linhaça, com valor médio de 28,9\%, seguido por xilose, galactose, ramnose e arabinose (HALL, TULBEK e XU, 2006).

A porção goma da linhaça constitui hidrocoloide de boa capacidade de ligação em água, devido à sua habilidade de inchamento e alta viscosidade em soluções aquosas (FEDENIUK e BILIADERIS, 1994; CHEN, XU e WANG, 2004). A goma também apresenta fracas propriedades do gel, assim, pode ser usada para substituir a maioria das gomas não gelificantes para aplicações alimentícias e não alimentares (CUI e MAZZA, 1996; CHEN, XU e WANG, 2006). Cui e Mazza (1996) evidenciaram que a viscosidade da goma da linhaça varia de 434 a $658 \mathrm{~mL} / \mathrm{g}$, diferenciandose das gomas arábica $(14,4 \mathrm{~mL} / \mathrm{g})$, guar $(1135 \mathrm{~mL} / \mathrm{g})$ e xantana $(1355 \mathrm{~mL} / \mathrm{g})$. Oomah e Mazza (1998) constataram que o conteúdo de carboidratos solúveis da linhaça, após processamento comercial, aumentou de 98,6 para $177,9 \mathrm{~g} / \mathrm{kg}$ em base seca.

A linhaça dourada contém menor quantidade de fibra total em relação à linhaça marrom, entretanto apresenta maiores teores de proteínas (BELL e KEITH, 1993).

Resultados de pesquisas sugerem correlação negativa entre o óleo e o conteúdo de diglicosídeo secoisolariciresinol (SDG). Frações com casca podem ser utilizadas como boa fonte de SDG, enquanto as descascadas devem ser processadas como óleo de linhaça (MADHUSUDHAN et al., 2000; WIESENBORN, TOSTENSON e KANGAS, 2003).

Os compostos fenólicos são amplamente distribuídos nas plantas. Em sementes oleaginosas, os compostos fenólicos ocorrem como derivados hidroxilados dos ácidos benzoico e cinâmico, cumarinas e compostos flavonoides. A linhaça contém 35 a $70 \mathrm{mg}$ de flavonoides/ $100 \mathrm{~g}$ (RIBEREAU-GAYON, 1972; OOMAH e MAZZA, 1998). Oomah, Kenaschuck e Mazza (1995) relataram que o total de ácido fenólico em oito cultivares canadenses variou de 790 a $1030 \mathrm{mg} / 100 \mathrm{~g}$.

Tocoferois, também, estão presentes na linhaça e consistem nos isômeros $\alpha, \beta, \gamma$, e $\delta$, considerados antioxidantes eficazes. Oomah, Kenaschuck e Mazza (1997) observaram que o $\mathrm{y}$-tocoferol $(9,04 \mathrm{mg} / 100 \mathrm{~g}$ de sementes) foi o isômero predominante nos cultivares de linhaça canadense. Afirmaram também, que o conteúdo $\gamma$-tocoferol na linhaça está relacionado ao alto conteúdo de ácido $\alpha$-linolênico.

Pretova e Vojtekova (1985) relataram a presença de luteína, $\beta$-caroteno e violaxantina na linhaça. Carotenoides podem servir como antioxidantes secundários dos radicais livres oxigênio singleto $\left({ }^{1} \mathrm{O}_{2}\right)$. Além disso, os carotenoides podem funcionar como antioxidantes quebrando a cadeia por interceptação de radicais livres nos lipídios na ausência de oxigênio singleto (BELITZ, GROSCH e SCHIEBERLE, 2004). Daun et al. (2003) constataram faixa de 0-2 mg/kg de clorofila na linhaça, a qual desapareceu durante a maturação.

Os esteroides são lipídios derivados do colesterol e estão presentes em células vegetais. Os maiores esterois na linhaça são estigmasterol, campesterol, e $\delta-5$ avenasterol (DAUN et al., 2003). Obtusifoliol, gramisterol e citrostadienol representaram $45 \%, 22 \%$ e $12 \%$, respectivamente, do total de $\alpha-4$ monometilesterois da linhaça (KAMM et al., 2001). O esqualeno, composto intermediário na biossíntese de esterois das plantas, exerce efeitos protetores na qualidade dos lipídios, podendo atuar como ligante de radicais peróxidos ou ácidos graxos PUFA. Seu conteúdo no óleo de linhaça é de $4 \mathrm{mg} / 100 \mathrm{~g}$ de óleo (DESSI et al., 2002).

A linhaça contém pequenas quantidades de vitaminas lipossolúveis $A, D, E$ e $K$ e hidrossolúveis, como a niacina e o ácido fólico e minerais, como potássio e fósforo (DAUN et al., 
2003; MORRIS e VAISEY-GENSER, 2003), diferindo conforme a variedade, cultivo, meio ambiente e métodos de análise (COSKUNER e KARABABA, 2007).

A composição química básica da linhaça pode ser visualizada na Tabela 1 e a composição físico-química do óleo de linhaça refinado na Tabela 2.

TABELA 1 - COMPOSIÇÃO QUÍMICA LINHAÇA (Linum usitatissimum L.)

\begin{tabular}{|c|c|c|}
\hline Nutrientes & Unidade & Valor por $100 \mathrm{~g}$ \\
\hline Água & $g$ & 8,75 \\
\hline Calorias & kcal & 492 \\
\hline Proteínas & g & 19,5 \\
\hline Lípides totais (gordura) & g & 34 \\
\hline Carboidratos, por diferença & g & 34,25 \\
\hline Fibra total dietética & g & 27,9 \\
\hline Cinzas & $g$ & 3,5 \\
\hline \multicolumn{3}{|l|}{ Minerais } \\
\hline Cálcio, Ca & $\mathrm{mg}$ & 199 \\
\hline Ferro, Fe & $\mathrm{mg}$ & 6,22 \\
\hline Magnésio, MG & $\mathrm{mg}$ & 362 \\
\hline Fósforo, $\mathrm{P}$ & $\mathrm{mg}$ & 498 \\
\hline Potássio, $\mathrm{K}$ & $\mathrm{mg}$ & 681 \\
\hline Sódio, $\mathrm{Na}$ & $\mathrm{mg}$ & 34 \\
\hline Zinco, Zn & $\mathrm{mg}$ & 4,17 \\
\hline Cobre, $\mathrm{Cu}$ & $\mathrm{mg}$ & 1,041 \\
\hline Manganês, Mn & $\mathrm{mg}$ & 3,281 \\
\hline Selênio, Se & $\mathrm{mcg}$ & 5,5 \\
\hline \multicolumn{3}{|l|}{ Vitaminas } \\
\hline Vitamina $\mathrm{C}$, ácido ascórbico total & $\mathrm{mg}$ & 1,3 \\
\hline Tiamina & $\mathrm{mg}$ & 0,17 \\
\hline Riboflavina & $\mathrm{mg}$ & 0,16 \\
\hline Niacina & $\mathrm{mg}$ & 1,4 \\
\hline Ácido pantotênico & $\mathrm{mg}$ & 1,53 \\
\hline Vitamina B6 & $\mathrm{mg}$ & 0,927 \\
\hline Folato total & $\mathrm{mcg}$ & 278 \\
\hline Vitamina B12 & $\mathrm{mcg}$ & 0 \\
\hline Vitamina A & UI & 0 \\
\hline Vitamina A, RAE & mcg_RAE & 0 \\
\hline \multicolumn{3}{|l|}{ Lipídios } \\
\hline Ácidos graxos, total saturados & $g$ & 3,196 \\
\hline Ácidos graxos, total MUFA & g & 6,868 \\
\hline Ácidos graxos, total PUFA & g & 22,44 \\
\hline Colesterol & $\mathrm{mg}$ & 0 \\
\hline Ácido Palmítico C16:0 & $\%$ & $5,7-7,0$ \\
\hline Ácido Esteárico C18:0 & $\%$ & $3,0-4,0$ \\
\hline Ácido Oleico (w9) C18:1 & $\%$ & $20,0-20,3$ \\
\hline Ácido Linoleico ( $\omega-6)$ C18:2 & $\%$ & $17,0-17,3$ \\
\hline Ácido $\alpha$-Linolênico $(\omega-3)$ C18:3 & $\%$ & $52,0-54,0$ \\
\hline Ácido Araquídico C20:0 & $\%$ & $<0,1$ \\
\hline
\end{tabular}

Fonte: USDA (2001); FIRESTONE (2006). 
A linhaça apresenta duas substâncias que podem interferir na absorção de certos nutrientes, embora em níveis que parecem ser de pouca importância na dieta humana. A linatina inibe a utilização de piridoxina (vitamina B6). O ácido fítico forma complexos insolúveis com cálcio, cobre, ferro, magnésio e zinco no intestino, reduzindo sua absorção. Não há evidência de que isso possa ocorrer em qualquer medida apreciável nos seres humanos (MORRIS e VAISEY-GENSER, 2003, TRUCOM, 2006).

A linhaça contém glicosídeos cianogênicos, grupo de substâncias naturais encontradas em mais de 2500 espécies de plantas que podem liberar cianeto (substância prejudicial, sob certas condições). Não há evidências claras de que os glicosídeos cianogênicos representem problema grave para a saúde. Métodos de processamento, principalmente a cocção, aparentemente destroem ou volatinizam esses compostos (MORRIS e VAISEY-GENSER, 2003).

\section{TABELA 2 - COMPOSIÇÃO FÍSICO-QUÍMICA DO ÓLEO DE LINHAÇA REFINADO}

\begin{tabular}{lcc}
\hline \multicolumn{1}{c}{ Índices } & Unidades & Valores de Referência \\
\hline Peso Específico $\left(25^{\circ} \mathrm{C}\right)$ & $\mathrm{g} / \mathrm{c} \mathrm{m}^{3}$ & $0,924-0,930$ \\
Índice de Refração $\left(25^{\circ} \mathrm{C}\right)$ & - & $1,477-1,482$ \\
Índice de lodo & $\mathrm{gl}_{2} / 100 \mathrm{~g}$ & $170-203$ \\
Índice de Saponificação & $\mathrm{mg} \mathrm{KOH} / \mathrm{g}$ & $188-196$ \\
Matéria Insaponificável & $\%$ & $0,1-2$ \\
Acidez, óleo bruto & $\mathrm{g}$ ácido oleico/100 g & $<3$ \\
Acidez, óleo refinado & $\mathrm{g}$ ácido oleico/100 g & $<0,15$ \\
Título & ${ }^{\circ} \mathrm{C}$ & $19-21$ \\
Cor (Gardner 1.953$)$ & - & 06 (Máximo) \\
Densidade $\left(25^{\circ}\right)$ & - & 0,926 a 0,931 \\
Viscosidade $($ Gardner $)$ & - & $\mathrm{A}$ (Máximo) \\
Aparência $\left(25^{\circ}\right)$ & - & Límpida \\
Odor & - & Característico \\
\hline
\end{tabular}

Fonte: FIRESTONE (2006).

\section{ASPECTOS SENSORIAIS}

Oomah (2001) e Hall e Schwarz (2002) afirmaram que a linhaça apresenta sabor agradável de nozes e cereais, ligeiramente amargo (CARTER, 1996; MORRIS e VAISEY-GENSER, 2003). No entanto, suas características sensoriais não foram bem avaliadas e a preferência no consumo do produto dependente da qualidade das sementes. Aparência, cor e atributos de sabor podem variar conforme o cultivar e condições de crescimento. A linhaça inteira fornece crocância e mastigabilidade, características de textura menos pronunciadas sob a forma de farinha (MORRIS e VAISEY-GENSER, 2003).

A moagem da linhaça aumenta a liberação dos voláteis, gerando melhor sabor e maior acessibilidade aos glicosídeos cianogênicos e componentes fenólicos, facilitando sua detecção pelos julgadores sensoriais, pois podem contribuir para o gosto amargo (CHIWONA-KARLTUN et al., 2004). 
A linhaça inteira permanece oxidativamente estável por muitos anos. No entanto, condições de alta umidade durante a armazenagem podem desencadear oxidação enzimática. Enzimas, como lipoxigenase (LOX), podem promover oxidação suficiente para afetar a qualidade da semente. Apenas os ácidos graxos insaturados (linoleico e a-linolênico) podem funcionar como substrato para a LOX, que produz hidroperóxidos nas posições C-13 (80\%) e C-9 $(20 \%)$ em substratos do ácido graxo linoleico. Com $88 \%$ do ácido graxo a-linolênico na posição C-13 e $12 \%$ na posição C-9 formam hidroperóxidos (ZIMMERMAN e VICK, 1970).

\section{PROCESSAMENTO E ARMAZENAMENTO}

O óleo de linhaça, geralmente, prensado a frio (ou bruto) tem coloração amarelo-dourado, marrom ou âmbar. Apresenta-se mais viscoso que a maioria dos óleos vegetais em razão de elevado teor de ácidos graxos insaturados (principalmente $\omega$-3) (TRUCOM, 2006). Temperaturas altas durante o processo a frio constituem preocupação para a indústria, porque a auto-oxidação pode ser desencadeada (WIESENBORN et al., 2004). Zheng et al. (2005) discutiram a energia mecânica específica durante a prensagem de sementes com casca e descascadas. Seus resultados indicaram que redução do teor de umidade da semente de linhaça (de 12,6\% para 6,3\%) provocou atrito entre as sementes, gerando aumento significativo na energia mecânica específica e calor. Sugeriram que o pré-tratamento da linhaça ajuda a reduzir a exposição do óleo a altas temperaturas e previne possíveis sabores desagradáveis. Assim, a fim de estabilizar os ácidos graxos $\omega-3$ durante o processo deve-se controlar a temperatura, mantendo-a tão baixa quanto possível. Todas as formas de aquecimento em excesso devem ser evitadas (SHUKLA, 2003).

Com conteúdo de água de 9-10\%, a vida-de-prateleira da linhaça inteira, geralmente, ultrapassa 12 meses de armazenamento (COSKUNER e KARABABA, 2007).

\section{RECOMENDAÇÕES NUTRICIONAIS}

Morris e Vaisey-Genser (2003) destacaram recomendações quanto ao consumo diário de linhaça para alcançar a ingestão de ácidos graxos ( $\omega-3$ e $\omega-6)$ com ótima razão entre $\omega-6 / \omega-3$. Assim, porções de $8 \mathrm{~g}$ ( 1 colher de sopa) de semente de linhaça moída ou 2,5 g (1/2 colher chá) de óleo de linhaça por dia oferecem as quantidades ideais. Entretanto, Tarpila et al. (2002) comentaram que o consumo de linhaça na dieta diária de até $20 \%$ de energia total tem sido recomendado para surtir efeitos relativos à promoção da saúde.

\section{ASPECTOS MICROBIOLÓGICOS E LEGAIS}

Apesar da legislação brasileira, RDC n¹2/2001 (BRASIL, 2001), não especificar limite para a contagem total de microrganismos para a linhaça, Fung et al. (1980) afirmaram que produtos com contagens entre $10^{5}$ e $10^{6} \mathrm{UFC/g}$ são considerados altamente contaminados e, consequentemente, impróprios para o consumo. Conforme Riedel (1992), qualquer microrganismo encontrado em alimentos em concentração superior a $10^{6}$ por grama ou mililitro é potencialmente prejudicial à saúde humana.

Em alguns raros estudos sobre a microbiologia da linhaça, efetuados no Brasil, foram encontradas bactérias aeróbias mesófilas totais, bolores e leveduras, coliformes a $45^{\circ} \mathrm{C}$, Salmonella spp., Bacillus cereus e fungos como Eurotium chevalieri, Wallemia sebi, A. candidus, A. niger, A. flavus, A. parasiticus, Fusarium sp., e levedura Cryptococcus Magnus (CASTRO et al., 2008; MORAIS et al., 2010).

A FAO (2004) divulgou regulamentação sobre micotoxina de vários países que, direta ou 
indiretamente, incluem frutas e vegetais (entre os quais a linhaça). Por exemplo, a Federação Russa determinou o limite de $5 \mathrm{mg} / \mathrm{kg}$ para a aflatoxina B1 no óleo de linhaça. Já, no Canadá foram estabelecidos vários valores toleráveis.

A Instrução Normativa $n^{\circ}$ 60, de 10 de dezembro de 2009, estabelece padrões de identidade e qualidade para a produção de sementes de várias espécies, entre as quais a Linum usitatissimum L. Entretanto, não menciona os aspectos físico-químicos e microbiológicos desse alimento (BRASIL, 2009). O seu registro junto a Agência Nacional de Vigilância Sanitária (ANVISA) para novos alimentos e novos ingredientes (BRASIL, 2010a) tem como requisito a comprovação da segurança de uso (BRASIL, 1999a,b).

Para os alimentos com alegações de propriedades funcionais e/ou de saúde (BRASIL, 2010b), a ANVISA estabelece que aqueles que apresentarem em seus dizeres de rotulagem e/ou material publicitário as alegações aprovadas devem ser registrados nas categorias de: "Alimentos com Alegações de Propriedade Funcional e ou de Saúde" ou de "Substâncias Bioativas e Probióticos Isolados com Alegação de Propriedades Funcional e ou de Saúde". Assim, devem ter registro prévio à comercialização (BRASIL, 2005).

\title{
9 CONSIDERAÇÕES FINAIS
}

A linhaça e seus subprodutos são considerados ótimas fontes de nutrientes importantes na dieta devido seus fatores de proteção, como as lignanas. Pesquisas recentes sugerem que sua ingestão desempenha papel relevante na prevenção de doenças crônicas não transmissíveis. Apesar disso, muitos consumidores são incapazes de incorporar esses alimentos como parte importante da dieta. Diante disso, a população deve ser encorajada a aumentar o consumo de linhaça e seus derivados, melhorando o seu estado nutricional mediante acesso a escolha de alimentos saudáveis, colaborando para a redução do risco de patologias.

\begin{abstract}
CHARACTERIZATION AND PROPERTIES OF LINSEED (Linum usitatissimun L.) AND BY-PRODUCTS

This literature review aimed to collect information concerning the properties and characteristics of flaxseed (Linum usitatissimun L.) and by-products for human consumption. The present study addressed aspects such as the origin, concept, physicochemical composition, sensory characteristics, processing and storage, nutritional recommendations and microbiological aspects as well as legal requirement. Regardless of flaxseed high nutritional value, due mostly to its high concentration of $\omega-3$, its consumption is still low as well as its addition in industrialized food products. Therefore a detailed study of its attributes becomes relevant in order to increase flaxseed intake considering its several benefits.
\end{abstract}

KEY-WORDS: FUNCTIONAL FOODS; FLAXSEED; NUTRITION.

\section{REFERÊNCIAS}

1 ABDEL-RAHMAN M.K.; MAHMOUD, E.M.; ABDEL-MOEMIN, A.R.; RAFAAT, O.G.A. Re-evaluation of individual and combined garlic and flaxseed diets on hyperlipidemic rats. Pakistan Journal of Nutrition, v.8, n.1, p.1-8, 2009.

2 ADLERCREUTZ, H.; FOTSIS, T.; BANNWART, C.; WÄHÄLÄ, K.; MÄKELÄ, T.; BRUNOW, G.; HASE, T. Determination of urinary lignans and phytoestrogen metabolites, potential antiestrogens and anticarcinogens, in urine of women of various habitual diets. Journal of Steroid Biochemistry, v.25, n.5B, p.791-797, 1986.

3 AHMED, S.Z. Physico-chemical, structural and sensory quality of corn-based flax-snack. Nahrung, v.43, n.4, p.253-258, 1999.

4 ANJO, D.L.C. Alimentos funcionais em angiologia e cirurgia vascular. Jornal Vascular Brasileiro, v.3, n.2, p.145-154, 2004. 
6 BELL, J.M.; KEITH, M.O. Nutritional evaluation of linseed meals from flax with yellow or brown hulls, using mice and pigs. Animal Feed Science and Technology, v.43, n.1-2, p.1-18, 1993.

7 BEMILLER, J.N. Quince seed, psyllium seed, flax seed and okra gums. In: WHISTLER, R.L.; BEMILLER, J.N. (Eds). Industrial gumes. $2^{\text {nd }}$ ed. New York: Academic Press, 1973.

8 BRASIL. Agência Nacional de Vigilância Sanitária. Resolução RDC nº 12, de 22 de setembro de 2005. Regulamento técnico sobre padrões microbiológicos para alimentos. Disponível em: <http://www.anvisa.gov.br/legis/resol/12_01rdc. htm> Acesso em: 27 jul. 2010.

9 BRASIL. Agência Nacional de Vigilância Sanitária. Resolução RDC n 16, de 30 de abril de 1999a. Regulamento técnico de procedimentos para o registro de alimentos e ou novos ingredientes. Disponível em: <http://www.engetecno. com.br/port/legislacao/rotulagem_registro_alimentos.htm>. Acesso em: 16 ago. 2010.

10 BRASIL. Agência Nacional de Vigilância Sanitária. Resolução RDC no 17, de 30 de abril de 1999b. Regulamento técnico que estabelece as diretrizes básicas para avaliação de risco e segurança dos alimentos. Disponível em: <http:// www.engetecno.com.br/port/legislacao/geral_alim_aval_risco.htm>. Acesso em: 16 ago. 2010.

11 BRASIL. Ministério da Agricultura, Pecuária e Abastecimento. Instrução Normativa № 60, de 10 de dezembro de 2009. Estabelece os padrões de identidade e qualidade para a produção de sementes das espécies: Brassica napus $L$. var. oleifera (canola); secale cereale I. (centeio) e hordeum vulgare I. (cevada); pisum sativum I. s.l. (ervilha); sesamum indicum I. (gergelim); corchorus capsularis I. e c. olitorius I. (juta); linum usitatissimum I. (linho); e nicotiana tabacum I. (tabaco). Disponível em: <http://extranet.agricultura.gov.br/sislegis-consulta/consultarLegislacao.do;jsessionid=3807195 571783092859c484aa85e 1a3d85b5ae066f0a4cffb65f7943fbbb363a.e3uQbh0LahaSe34Pbh0Kbx0Mahn0?operacao=vi sualizar\&id=21236>. Acesso em: 12 set. 2010.

12 BRASIL. Agência Nacional de Vigilância Sanitária. Resolução RDC n 278, de 22 de setembro de 2005. Aprova as categorias de alimentos e embalagens dispensadas e com obrigatoriedade. Disponível em: <http://abenutri.org/ yahoo_site_admin/assets/docs/RDC_278_2005.24771432.pdf>. Acesso em: 18 ago. 2010.

13 BRASIL. Agência Nacional de Vigilância Sanitária. Resolução $n^{\circ}$ 16, de 30 de abril de 1999. Determina a rotulagem de novos alimentos e novos ingredientes. Disponível em: < http://www.engetecno.com.br/port/legislacao/rotulagem_regi stro_alimentos.htm>. Acesso em: 02 mai. 2010a.

14 BRASIL. Agência Nacional de Vigilância Sanitária. Resolução $n^{\circ}$ 19, de 30 de abril de 1999. Dispõe sobre alimentos com alegações de propriedades funcionais e ou de saúde. Disponível em: < http://www.engetecno.com.br/port/ legislacao/geral_alim_alegacoes.htm >. Acesso: mai. 2010b.

15 CANADIAN GRAIN COMMISSION. Canada Western flaxseed and of yellow flaxseed samples. Manitoba, 2001. (Nutritional profile of n.1 Winnipeg).

16 CARRARA, C.L.; ESTEVES A.P.; GOMES, R.T.; GUERRA, L.L. Uso da semente de linhaça como nutracêutico para prevenção e tratamento da arterosclerose. Revista Eletrônica de Farmácia, v.4, p.1-9, 2009.

17 CARTER, J.F. Potential of flaxseed and flaxseed oil in baked goods and other products in human nutrition. Cereal Foods World, v.38, n.10, p.753-759, 1993.

18 CARTER, J.F. Sensory evaluation of flaxseed of different varieties. Proceedings Flax Institute, v.56, n.1, p.201-203, 1996.

19 CASTRO, I.A.; BARROSO, L.P.; SINNECKER, P. Functional foods for coronary heart disease risk reduction: a metaanalysis using a multivariate approach. The American Journal of Clinical Nutrition, v.82, n.1, p.32-40, 2005.

20 CASTRO, R.J.S.; MACIEL, T.C.; MARTINS, S. Avaliação da qualidade microbiológica de linhaça como parâmetro de qualidade e segurança alimentar. In: CONGRESSO DE PESQUISA E INOVAÇÃO DA REDE NORTE NORDESTE DE EDUCAÇÃO TECNOLÓGICA, 3., 2008, Fortaleza. Anais... Fortaleza: Educação Tecnológica, 2008.

21 CHEN, H.H.; XU, S.Y.; WANG, Z. Gelation properties of flaxseed gum. Journal of Food Engineering, v.77, n.2, p.295303, 2006.

22 CHEN, H.H.; XU, S.Y.; WANG, Z. Separation and purification of acidic polysaccharides and neutral polysaccharides in flaxseed gum. Journal of Food and Fermentation Industry, v.30, n.1, p.96-100, 2004.

23 CHIWONA-KARLTUN, L.; BRIMER, L.; KALENGA SAKA, J.D.; MHONE, A.R.; MKUMBIRA, J.; JOHANSSON, L.; BOKANGA, M.; MAHUNGU, N.M.; ROSLING, H. Bitter taste in cassava roots correlates with cyanogenic glucoside levels. Journal of the Science of Food and Agriculture, v.84, n.6, p.581-590, 2004.

24 COSKUNER, Y.; KARABABA, E. Some physical properties of flaxseed (Linum usitatissimum L.). Journal of Food Engineering, v.78, n.3, p.1067-1073, 2007. 
25 CREDIDIO, E. Propriedades nutricionais da linhaça. 2005. Disponível em: <http://www.abran.org.br/inf_artigos/ 123. htm>. Acesso em: 21 abr. 2010.

26 CUI, W.; MAZZA, G. Physicochemical characteristics of flaxseed gum. Food Research International, v.29, n.3-4, p.39740, 1996.

27 CUI, W.; MAZZA, G.; BILIADERIS, C.G. Chemical structure, molecular size distribution and rheological properties of flaxseed gum. Journal of Agriculture and Food Chemistry, v.42, n.9, p.1891-1895, 1994.

28 CUNNANE, S.C.; HAMADEH, M.J.; LIEDE, A.C.; THOMPSON, L.U.; WOLEVER, T.M.; JENKINS, D.J. Nutritional attributes of traditional flaxseed in healthy young adults. The American Journal of Clinical Nutrition, v.61, n.1, p.62-68, 1995.

29 DAUN, J.K.; BARTHET, V.J.; CHORNICK, T.L.; DUGUID, S. Structure, composition, and variety development of flaxseed. In: THOMPSON, L.U.; CUNNANE, S.C. Flaxseed in human nutrition. $2^{\text {nd }}$ ed. Champaign IL.: AOCS Press, 2003. p.140 .

30 DESSI, M.A.; DEIANA, M.; DAY, B W.; ROSA, A.; BANNI, S.; CORONGIU, F.P. Oxidative stability of polyunsaturated fatty acids: effect of squalene. European Journal of Lipid Science, v.104, n.8, p.506-512, 2002.

31 FAO. Food and Agriculture Organization. Worldwide regulations for mycotoxins in food and feed in 2003. Rome, 2004. 170 p. (Food and Nutrition Paper, 81).

32 FEDENIUK, R.W.; BILIADERIS, C.G. Composition and physicochemical properties of linseed mucilage. Journal of Agriculture and Food Chemistry, v.42, n.2, p.240-247, 1994.

33 FIRESTONE, D. AOCS catalog, physical and chemical characteristics of oils, fats, and waxes. $2^{\text {nd }}$ ed. Boulder, USA: AOCS Press, 2006. 237 p

34 FITZPATRICK, K. North America flax facts important questions \& answers for improved health and nutrition. $2^{\text {nd }}$ ed. Revised May 2006. Disponível em: <http://www.ameriflax.com/UserFiles/Image/Flax_Facts_II.pdf>. Acesso em: 29 jul. 2010

35 FLAX COUNCIL OF CANADA. Statistics. 2010. Disponível em: <http://www. flaxcouncil.ca/english/index.jsp?p=statistic s2\&mp=statistics>. Acesso em: 14 jul. 2010.

36 FREEMAN, T.P. Structure of flaxseed. In: CUNNANE, S.C.; THOMPSON, L.U. (Eds.). Flaxseed in human nutrition. Champaign, IL: AOCS Press, 1995. p.11-21.

37 FUNG, D.Y.C.; KASTNER, C.L.; HUNT, M.C.; DIKEMAN, M.E.; KROPK, D. Mesophilic and psychrotrophyc bacteria population on hot-boned and conventionally processed beef. Journal of Food Protection, v.43, n.7, p.547-550, 1980.

38 GRIEL, A.E.; KRIS-ETHERTON, P.M.; HILPERT, K.F.; ZHAO, G.; WEST, S.G.; CORWIN, R.L. An increase in dietary n-3 fatty acids decreases a marker of bone resorption in humans. Nutrition Journal, v.6, n.1, p.2-10, 2007.

39 GUBBELS, G.H.; BONNER, D.M.; KENASCHUK, E.O. Effect of frost injury on quality of flax seed. Canadian Journal of Plant Science, v.74, n.2, p.331-333, 1994.

40 GUILLEVIC, M.; KOUBA, M.; MOUROT, J. Effect of a linseed diet on lipid composition, lipid peroxidation and consumer evaluation of French fresh and cooked pork meats. Meat Science, v.81, n.4, p.612-618, 2009.

41 HALL, C; SCHWARZ, J. Functionality of flaxseed in frozen desserts-preliminary report. FLAX - a health and nutrition primer 103. Proceedings of Flax Institute, v.59, p.21-24, 2002.

42 HALL, III.C.; TULBEK, M.C.; XU, Y. Flaxseed. In: TAYLOR, S. (Eds.). Advances in food and nutrition research (51). San Diego, CA: Academic Press, 2006. Chapter 1, p.1-97.

43 HELBAEK, H. Plant collecting, dry-farming, and irrigation agriculture in prehistoric Deh Luran. In: HOLE, F.; FLANNERY, K.; NEELY, J. (Eds.). Prehistory and human ecology of the Deh Luran Plain. Ann Arbor: University of Michigan, 1969. p.386-426. (Memoirs of the Museum of Anthropology, Memoir 1).

44 HILLMAN, G.C.; COLLEDGE. S.M.; HARRIS. D.R. Plant-food economy during the epipalaeolithic period at Tell Abu Hureyra. Syria: dietary diversity, seasonality, and modes of exploitation. In: HARRIS D.R.; HILLMAN, O.H. (Eds.). Foraging and farming: the evolution of plant exploitation. London: Unwin \& Hyman, 1989. p.240-268.

45 HILLMAN, O. The plant remains from Tell Abu Hureyra: a prelimmnary report. Proceedings of the Prehistoric Society, v.41, n.1, p.70-73, 1975 .

46 HOPF, M. Jericho plant remains. In: KENYON K.M.; HOLLAND T.A. (Eds). Excavations al Jericho. London: British School of Archaeology in Jerusalem, 1969. v.5, p.576-621.

47 HUSSAIN, S.; ANJUM, F.M.; BUTT, M.S.; KHAN, M.I.; ASGHAR, A. Physical and sensoric attributes of flaxseed flour supplemented cookies. Turkish Journal of Biology, v.30, n.1, p.87-92, 2006. 
48 JACINTO, K.A. Efeito do consumo de farinha de linhaça (Linum usitatissimum L.) no crescimento de ratos wistar e sua relação com a digestibilidade de globullinas e fatores antinutricionais protéicos nas albuminas. $2007.82 \mathrm{f}$. Dissertação (Mestrado em Bioquímica) - Centro de Ciências Biológicas, Universidade Federal do Rio Grande do Norte, Natal, 2007.

49 JUDD, J.T.; BAER, D.J.; CLEVIDENCE, B.A.; MUESING, R.A.; CHEN, S.C.; WESTSTRATE, J.A.; MEIJER, G.W.; WITTES, J.; LICHTENSTEIN, A.H.; VILELLA-BACH, M.; SCHAEFER, E.J. Effects of margarine compared with those of butter on blood lipid profiles related to cardiovascular disease risk factors in normolipemic adults fed controlled diets. The American Journal of Clinical Nutrition, v.68, n.4, p.768-777, 1998.

50 KAMM, W.; DIONISI, F; HISCHENHUBER, C.; ENGEL, KARL-HEINZ. Authenticity assessment of fats and oils. Food Reviews International, v.17, n.3, p.249-290, 2001.

51 KOZLOWSKA, J. The use of flax seed for food purposes. In: EUROPEAN REGIONAL WORKSHOP ON FLAX, Poznan, 1989. Proceedings... Poznan, Poland: FAO, 1989. p.189-199.

52 KRAUSE, J.P.; SCHULTZ, M.; DUDEK, S. Effect of extraction conditions on composition, surface activity and rheological properties of protein isolates from flaxseed (Linum usitativissimum $L$ ). Journal of the Science of Food and Agriculture, v.82, n.9, p.970 - 976, 2002.

53 KURZER, M.S.; XU, X. Dietary phytoestrogens. Annual Reviews of Nutrition, v.17, n.1, p.353-381, 1997.

54 LEE, K.W.; LIP, G.Y.H. The role of omega-3 fatty acids in the secondary prevention of cardiovascular disease. QJM Monthly Journal of The Association of Physicians, v.96, n.7, p.465-480, 2003.

55 LEE, S.; INGLETT, G.E.; CARRIERE, C.J. Effect of Nutrim oat bran and flaxseed on rheological properties of cakes. Cereal Chemistry, v.81, n.5 p.637-642, 2004.

56 LIMA, J.R. Caracterização físico-química e sensorial de hambúrguer vegetal elaborado à base de caju. Ciência e Agrotecnologia, v.32, n.1, p.191-195, 2008.

57 MACIEL, L.M.B.; PONTES, D.F.; RODRIGUES, M.C.P. Efeito da adição de farinha de linhaça no processamento de biscoito tipo cracker. Alimentos e Nutrição, v.19, n.4, p.385-392, 2008.

58 MADHUSUDHAN, B. Potential benefits of flaxseed in health and disease - a perspective. Agriculturae Conspectus Scientificus, v.74, n.2, p.67-72, 2009.

59 MADHUSUDHAN, B.; WIESENBORN, D.; SCHWARZ, J.; TOSTENSON, K.; GILLESPIE, J. A dry mechanical method for concentrating the lignan Secoisolariciresinol Diglucoside in flaxseed. Lebensmittel-Wissenschaft und-Technologie, v.33, n.4, p.268-275, 2000 .

60 MADHUSUDHAN, K.T.; SINGH, N. Studies on linseed proteins. Journal of Agricultural and Food Chemistry, v.31, n.5, p.959-963, 1983

61 MARCONE, M.F.; KAKUDA, Y.; YADA, R. Y. Salt-soluble seed globulins of dicotyledonous and monocotyledonous plants. II. Structural characterization. Food chemistry, v.62, n.1, p.27-47, 1998.

62 MORAIS, V.A.D. et al. Linhaça - alimento seguro? Fundação Ezequiel Dias, Instituto Octávio Magalhães, Divisão de Vigilância Sanitária. Disponível em: < http://www.hbatools.com.br/congresso/trabalho/42/VANESSA_MORAIS_ CPF 27594726634-ENVIO_8-6-2009_16-40-46.doc>. Acesso em: 30 jul. 2010.

63 MORRIS, D.H. Flax - a health and nutrition primer. $4^{\text {th }}$ ed. Winnipeg, MB: Flax Council of Canada, 2007. $106 \mathrm{p}$.

64 MORRIS, D.H.; VAISEY-GENSER, M. Flaxseed. Encyclopedia of Food Sciences and Nutrition, v.10, n.2, p.25252531,2003

65 OOMAH B.D.; MAZZA, G. Flaxseed products for disease prevention. In: MAZZA, G. (Eds.). Functional foods: biochemical \& processing aspects. Lancaster, PA: Technomic Publishing, 1998. p.91-138.

66 OOMAH, B.D. Flaxseed as a functional food source. Journal of the Science of Food and Agriculture, v.81, n.9, p.889894, 2001.

67 OOMAH, B.D.; DER, T.J.; GODFREY, D.V. Thermal characteristics of flaxseed (Linum usitatissimum L.) proteins. Food Chemistry, v.98, n.4, p.733-741, 2006.

68 OOMAH, B.D.; KENASCHUCK, E.O.; MAZZA, G. Phenolic acids in flaxseed. Journal of Agricultural and Food Chemistry, v.43, n.8, p.2016-2019, 1995

69 OOMAH, B.D.; MAZZA, G. Effect of dehulling on chemical composition and the physical properties of flaxseed. Lebensmittel-Wissenschaft und-Technologie, v.30, n.2, p.135-140, 1997. 
70 OOMAH, B.D.; MAZZA, G. Flaxseed proteins - a review. Food Chemistry, v.48, n.1, p.109-114, 1993.

71 OOMAH, B.D.; KENASCHUK, E.O.; MAZZA, G. Tocopherols in flaxseed. Journal of Agricultural and Food Chemistry, v.45, n.6, p.2076-2080 1997.

72 PAN, A. YU, D.; DEMARK-WAHNEFRIED, W.; FRANCO, O.H.; LIN, X. Meta-analysis of the effects of flaxseed interventions on blood lipids. The American Journal of Clinical Nutrition, v.90, n.2, p.288-297, 2009.

73 PRETOVA, A.; VOJTEKOVA, M. Chlorophylls and carotenoids in flax embryos during embryogenesis. Photosynthetica, v.19, n.2, p.194-197, 1985.

74 RANICH, T.; BHATHENA, S.J.; VELASQUES, M.T. Protective effects of dietary phytoestrogens in chronic renal disease. Journal of Renal Nutrition, v.11, n.4, p.183-193, 2001.

75 RIBEREAU-GAYON, P. Plant phenolics. Edinburg: Oliver and Boyd, 1972. 254 p.

76 RIEDEL, G. Controle sanitário dos alimentos. 2. ed. São Paulo: Atheneu, 1992. 320 p.

77 ROLLEFSON, G.O. et al. Excavations at the pre-pottery neolithic B village of Ain Ghazal (Jordan), (1983). Mitteilungen der Deutschen Orient Gesellschaft, v.117, n.1, p.69-116, 1985.

78 ROY, H.J.; LUNDY, S.; ERIKSEN, C. Healthier lives through education in nutrition and preventive medicine. Flaxseed a review of health benefits. Pennington Nutrition Series, n.5, p.1-4, 2007.

79 RUDKOWSKA, I.; JONES, P.J. Functional foods for the prevention and treatment of cardiovascular diseases: cholesterol and beyond. Expert Review of Cardiovascular Therapy, v.5, n.3, p.477-90, 2007.

80 SAMMOUR, R.H. Proteins of linseed (Linum usitatissimum L.), extraction and characterization by electrophoresis. Botanical Bulletin of Academia Sinica, v.40, n.1, p.121-126, 1999.

81 SANTOS, C.; HOZ, L.; CAMBERO, M.I.; CABEZA, M.C.; ORDÓÑEZ, J.A. Enrichment of dry-cured ham with $\alpha$-linolenic acid and $\alpha$-tocopherol by the use of linseed oil and $\alpha$-tocopheryl acetate in pig diets. Meat Science, v.80, n.3, p.668-674, 2008.

82 SHUKLA, V.K.S. A designer oil for better health. International News on Fats, Oils, and Related Materials, v.14, n.6, p.340-341, 2003.

83 SPENCE, J.D.; THORNTON, T.; MUIR, A.D.; WESTCOTT, N.D. The effect of flax seed cultivars with differing content of $\alpha$-linolenic acid and lignans on responses to mental stress. Journal of the American College of Nutrition, v.22, n.6, p.494-501, 2003.

84 STITT, P.A. History of flax: 9000 years ago to 1986. In: PROCCEDINGS of 55th Flax Institute of the United States. Fargo, ND: Flax Institute of the United States, 1994. p.152-153.

85 TARPILA, S.; ARO, A.; SALMINEN, I.; TARPILA, A.; KLEEMOLA, P.; AKKILA, J.; ADLERCREUTZ, H. The effect of flaxseed supplementation in processed foods on serum fatty acids and enterolactone. European Journal of Clinical Nutrition, v.56, n.2, p.157-165, 2002.

86 THOMPSON, L.U.; CHEN, J.M.; LI, T.; STRASSER-WEIPPL, K.; GOSS, P.E. Dietary flaxseed alters tumor biological markers in postmenopausal breast cancer. Clinical Cancer Research, v.11, n.10, p.3828-3835, 2005.

87 TRUCOM, C. A importância da linhaça na saúde. São Paulo: Alaúde, 2006. 151 p.

88 USDA. United State Department of Agriculture. Nutrient database for standard reference. Release 14. Washington, 2001.

89 VALENCIA, I.; O'GRADY, M.N.; ANSORENA, D.; ASTIASARÁN, I.; KERRY, J.P. Enhancement of the nutritional status and quality of fresh pork sausages following the addition of linseed oil, fish oil and natural antioxidants. Meat Science, v.80, n.4, p.1046-1054, 2008.

90 VAN ZEISTE, W. Paleobotanical results of the 1970 season at Çayönü, Turkey. Helinium, v.12, n.1, p.3-19, 1972.

91 WANASUNDARA, P.K.J.P.D.; WANASUNDARA, I.J.N.; SHAHIDI, F. Changes in flax (Linum usitatissimum L.) seed lipids during germination. Journal of the American Oil Chemists' Society, v.76, n.1, p.41-48, 1999.

92 WARRAND, J.; MICHAUD , P.; PICTON, L.; MULLER, G.; COURTOIS, B.; RALAINIRINA, R.; COURTOIS, J. Structural investigations of the neutral polysaccharide of Linum usitatissimum $L$. seeds mucilage. International Journal of Biological Macromolecules, v.35, n.3-4, p.121-125, 2005.

93 WHO. World Health Organization. FAO. Food Agriculture Organization. WHO and FAO joint consultation: fats and oils in human nutrition. Nutrition Reviews, v.53, n.7, p.202-205, 1995. 
94 WIESENBORN, D.; DODDAPANENI, R.; TOSTENSON, K.; KANGAS, N. Kinetic characterization of cooking-induced changes in crambe seed prepared for expelling. Journal of Food Engineering, v.55, n.2, p.157-163, 2002.

95 WIESENBORN, D.; TOSTENSON, K.; KANGAS, N. Continuous abrasive method for mechanically fractionating flaxseed. Journal of the American Oil Chemists Society, v.80, n.3, p.295-300, 2003.

96 WIESENBORN, D.P.; ZHENG, Y.; KANGAS, N.; TOSTENSON, K.; HALL C.; CHANG, K.C. Quality of screw-pressed flaxseed oil. In: PROCEEDINGS of the 60th Flax Institute of the United States. Fargo, ND: Flax Institute of the United States, 2004. p.8-14.

97 ZHAO, G.; ETHERTON, T.D.; MARTIN, K.R.; WEST, S.G.; GILLIES, P.J.; KRIS-ETHERTON, P.M. Dietary a-linolenic acid reduces inflammatory and lipid cardiovascular risk factors in hypercholesterolemic men and women. Journal of Nutrition, v.134, n.11, p.2991-2997, 2004.

98 ZHENG, Y.L.; WIESENBORN, D.P.; TOSTENSON, K.; KANGAS, N. Energy analysis in the screw pressing of whole and dehulled flaxseed. Journal of Food Engineering, v.66, n.2, p.193-202, 2005.

99 ZIMMERMAN, D.C.; VICK, B.A. Specificity of flaxseed lipoxidase. Lipids, v.5, n.4, p.392-397, 1970. 